\title{
Safety and efficacy of tolcapone in Parkinson's disease: systematic review
}

\author{
Carlo Alberto Artusi $^{1}$ (1) $\cdot$ Lidia Sarro $^{2} \cdot$ Gabriele Imbalzano $^{1} \cdot$ Margherita Fabbri $^{3} \cdot$ Leonardo Lopiano $^{1}$
}

Received: 18 August 2020 / Accepted: 28 December 2020 / Published online: 7 January 2021

(C) The Author(s) 2021

\begin{abstract}
Purpose Tolcapone is an efficacious catechol-O-methyltransferase inhibitor for Parkinson's disease (PD). However, safety issues hampered its use in clinical practice. We aimed to provide evidence of safety and efficacy of tolcapone by a systematic literature review to support clinicians' choices in the use of an enlarging PD therapeutic armamentarium.

Methods We searched PubMed for studies on PD patients treated with tolcapone, documenting the following outcomes: liver enzyme, adverse events (AEs), daily Off-time, levodopa daily dose, unified Parkinson's disease rating scale (UPDRS) part-III, quality of life (QoL), and non-motor symptoms. FAERS and EudraVigilance databases for suspected AEs were interrogated for potential additional cases of hepatotoxicity.

Results Thirty-two studies were included, for a total of 4780 patients treated with tolcapone. Pertaining safety, $0.9 \%$ of patients showed liver enzyme elevation $>2$. Over 23 years, we found 7 cases of severe liver injury related to tolcapone, 3 of which were fatal. All fatal cases did not follow the guidelines for liver function monitoring. FAERS and EudraVigilance database search yielded 61 reports of suspected liver AEs possibly related to tolcapone.

Pertaining efficacy, the median reduction of hours/day spent in Off was 2.1 (range 1-3.2), of levodopa was $108.9 \mathrm{mg}$ (1251.5), of "On" UPDRS-III was 3.6 points (1.1-6.5). Most studies reported a significant improvement of QoL and non-motor symptoms.

Conclusion Literature data showed the absence of relevant safety concerns of tolcapone when strict adherence to hepatic function monitoring is respected. Given its high efficacy on motor fluctuations, tolcapone is probably an underutilized tool in the therapeutic PD armamentarium.
\end{abstract}

Keywords Tolcapone $\cdot$ Catechol-O-methyltransferase $\cdot$ Parkinson's disease $\cdot$ Safety $\cdot$ Efficacy $\cdot$ Liver

\section{Introduction}

Tolcapone (3,4-dihydroxy-4'-methyl-5-nitrobenzophenone) was approved in 1997 by the European Medicines Agency and in 1998 by the Food and Drug Administration as the first

Carlo Alberto Artusi

caartusi@gmail.com

1 Department of Neuroscience "Rita Levi Montalcini”, University of Torino, Via Cherasco 15, 10126 Torino, Italy

2 Department of Neurology, Martini Hospital, ASL Città di Torino, Torino, Italy

3 Department of Neurosciences, Clinical Investigation Center CIC 1436, Parkinson Toulouse Expert Center, NS-Park/FCRIN Network and NeuroToul COEN Center, Toulouse University Hospital; INSERM; University of Toulouse 3, Toulouse, France levodopa add-on catechol-O-methyltransferase (COMT) inhibitor for the treatment of Parkinson's disease (PD) patients with motor fluctuations [1]. The selective and reversible inhibition of COMT exploited by tolcapone leads to a reduction of the levodopa catabolism to 3-O-methyldopa, resulting in higher availability of dopamine into the brain [2]. As a consequence, the administration of tolcapone as an adjunct to levodopa improves motor fluctuations in PD patients, allowing a significant reduction of daily time spent in Off and total daily dose of levodopa [3].

Tolcapone differentiates from the two other COMT inhibitors available (entacapone and opicapone) for its lipophilic structure, which allows it to cross the blood-brain barrier and act into the central nervous system, exploiting its function both in the periphery and in the brain (Fig. 1) [4, 5]. Clinically, comparative data between entacapone and tolcapone showed higher efficacy of the latter [3]. 
Fig. 1 Mechanism of action of tolcapone

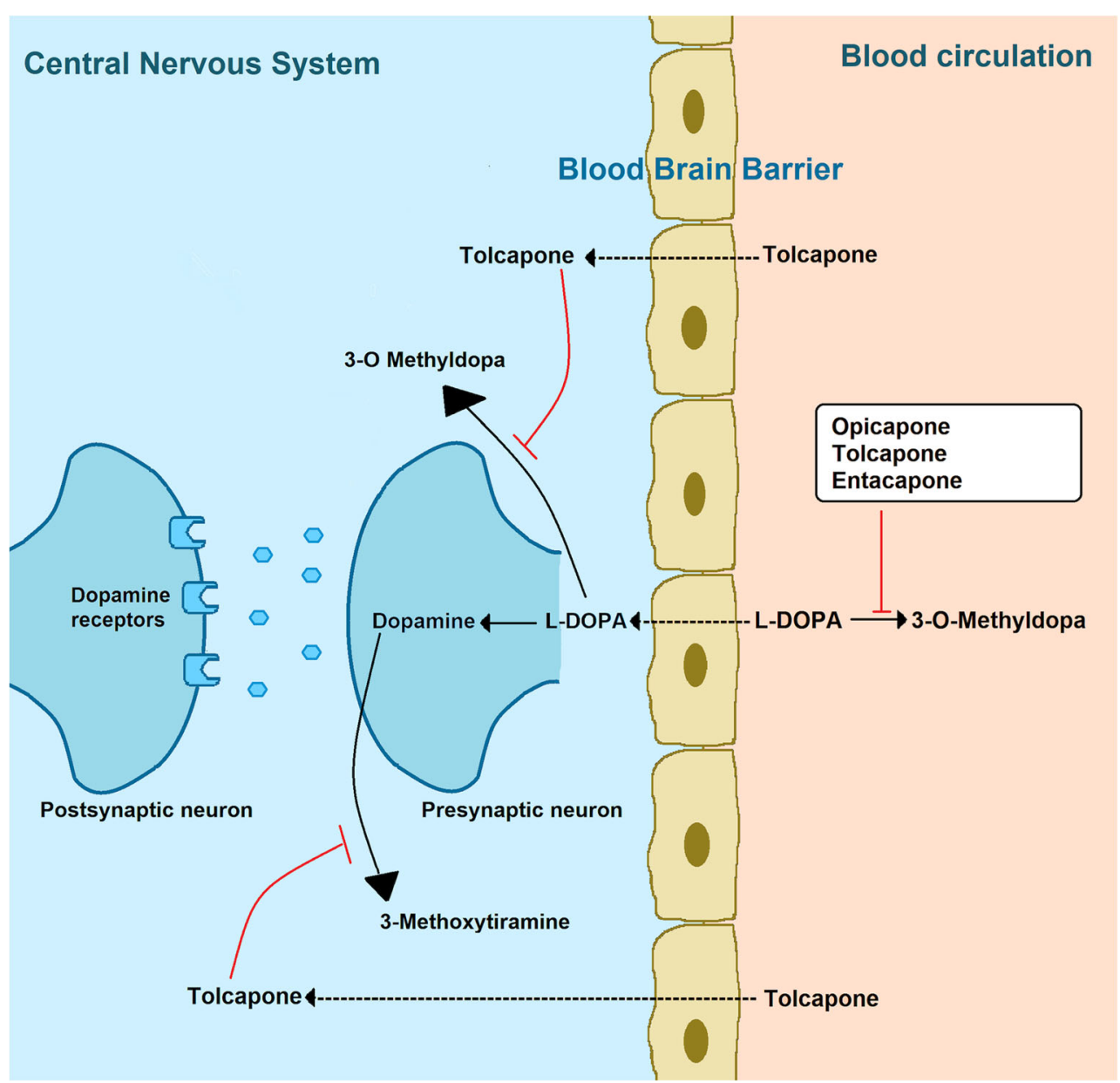

Conversely, there are no studies comparing the efficacy of tolcapone and the recently marketed opicapone, although indirect data seem to indicate at least a non-inferiority of tolcapone. However, a few albeit relevant safety concerns related to the tolcapone potential hepatotoxicity have restricted its use in the clinical practice, with its prescription that should be limited to levodopa-responsive idiopathic PD patients with motor fluctuations, who failed to respond to or are intolerant of other COMT inhibitors (Fig. 2) [6] (https://www.ema. europa.eu/en/documents/product-information/tasmar-eparproduct-information_en.pdf).

In this systematic review, we aimed to provide a comprehensive and updated overview of risks and potentiality linked to the use of tolcapone, beyond 20 years from its breakthrough in the PD drug armamentarium.

\section{Methods}

\section{Search method}

We conducted a systematic review following the Preferred Reporting Items for Systematic Reviews and Meta-analyses
(PRISMA) (Supplementary Table 1) [7]. We searched PubMed for interventional and noninterventional (i.e., observational) studies prior to February 1, 2020 reporting data on patients with a diagnosis of idiopathic PD treated with tolcapone using the following searching string: "tolcapone AND Parkinson's disease."

Abstracts and full-text articles were independently reviewed for eligibility criteria by two authors (C.A.A., L.S.). Duplicated studies were identified and excluded. Only studies referring to human subjects and published in English were considered. No restrictions were applied to sex, age, disease duration, disease severity, or follow-up. The reference list of each article was further screened for additional pertinent studies not captured by the original search strategy.

Moreover, the "FDA Adverse Event Reporting System (FAERS)" (https://www.fda.gov/drugs/questions-andanswers-fdas-adverse-event-reporting-system-faers/fdaadverse-event-reporting-system-faers-public-dashboard) and the "EudraVigilance - European database of suspected sideeffect reports" (http://www.adrreports.eu/en/index.html) databases were interrogated at May, 15th for serious adverse events (AEs) potentially related to tolcapone to search for 


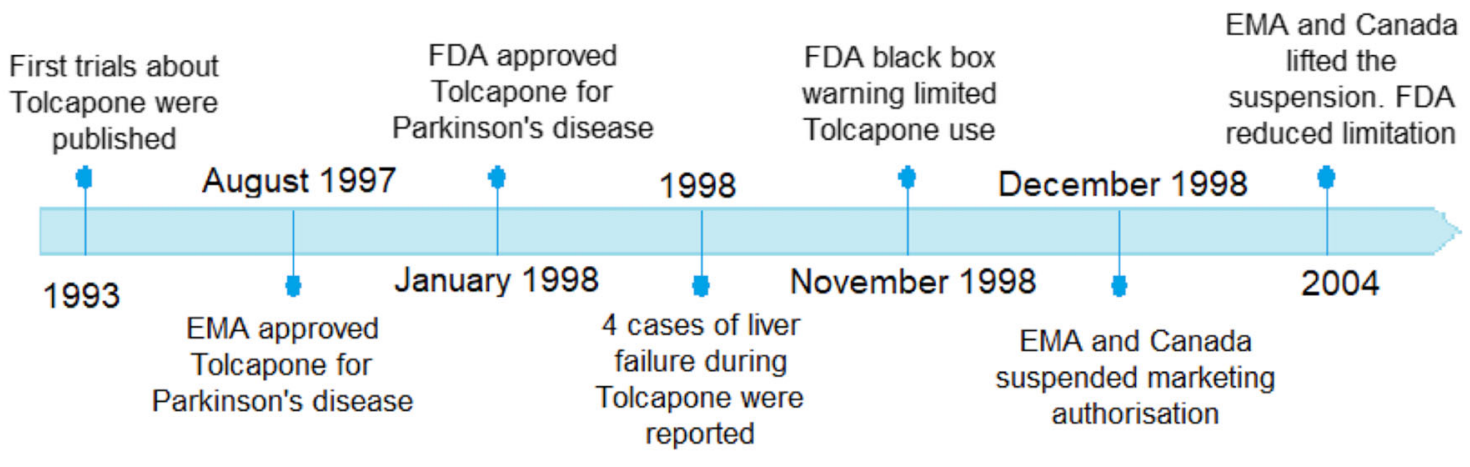

\begin{tabular}{|l|l|}
\hline \multicolumn{1}{|c|}{ Current safety indications - EMA } & \multicolumn{1}{c|}{ Current safety indications - FDA } \\
\hline $\begin{array}{l}\text { Tolcapone should not be first choice of treatment for } \\
\text { motor fluctuations in Parkinson's disease }\end{array}$ & $\begin{array}{l}\text { Tolcapone should not be first choice of treatment for } \\
\text { motor fluctuations in Parkinson's disease } \\
\text { Tolcapone should be discontinued if substantial clinical } \\
\text { The patient who fails to show substantial clinical benefit } \\
\text { within 3 weeks of initiation of treatment, should be } \\
\text { the treatment regardless of dose. }\end{array}$ \\
$\begin{array}{l}\text { Check liver function before starting treatment with } \\
\text { Tolcapone. If liver function tests are abnormal or there } \\
\text { are signs of impaired liver function, Tolcapone should not } \\
\text { be prescribed }\end{array}$ & $\begin{array}{l}\text { Liver enzymes test before starting therapy. Don't start } \\
\text { therapy if the patient exhibits clinical evidence of liver } \\
\text { disease or two ALT or AST values greater than the ULN }\end{array}$ \\
$\begin{array}{l}\text { Liver function should be monitored every } 2 \text { weeks for the } \\
\text { first year of therapy, every } 4 \text { weeks for the next } 6 \text { months } \\
\text { and every } 8 \text { weeks thereafter }\end{array}$ & $\begin{array}{l}\text { Periodic control of liver enzymes (i.e. every } 2 \text { to } 4 \text { weeks) } \\
\text { for the first } 6 \text { months of therapy. After the first six months, } \\
\text { periodic monitoring is recommended at intervals deemed } \\
\text { clinically relevant }\end{array}$ \\
$\begin{array}{l}\text { If the dose is increased to } 200 \text { mg tid, liver enzyme } \\
\text { monitoring should take place before increasing the dose } \\
\text { and then be reinitiated following the same sequence of } \\
\text { frequencies as above }\end{array}$ & $\begin{array}{l}\text { If the dose is increased to 200 mg tid, liver enzyme } \\
\text { monitoring should take place before increasing the dose } \\
\text { and then be reinitiated following the same sequence of } \\
\text { frequencies as above }\end{array}$ \\
$\begin{array}{l}\text { Discontinuation if ALT and/or AST exceed the ULN or } \\
\text { symptoms or signs suggest the onset of hepatic failure }\end{array}$ & $\begin{array}{l}\text { Discontinuation if ALT or AST levels exceed } 2 \text { times the } \\
\text { ULN or if clinical signs and symptoms suggest the onset } \\
\text { of hepatic dysfunction }\end{array}$ \\
\hline
\end{tabular}

Fig. 2 Tolcapone: history and current indications

potential additional cases of hepatotoxicity not published or not obtained by the PubMed database search.

\section{Study selection}

We included studies assessing the effect of tolcapone as an add-on therapy to levodopa in patients with a diagnosis of idiopathic PD, and reporting data on efficacy or safety. Specifically, we included all studies reporting at least one of the following outcomes: liver enzyme, tolcapone-related AEs, daily Off-time, levodopa daily dose (mg), UPDRS part-III, non-motor PD symptoms as per validated scales, quality of life (QoL) as per validated scales. Previously published literature reviews were excluded, as well as book chapters, letters to the editor, and editorials not providing original data.

\section{Data extraction}

Included studies were divided per study design, and for the use of a placebo or active control group when appropriate. We used a standardized data collection form to extract relevant data on safety and efficacy. The following information was extracted from each study where available: liver enzyme elevation (evaluated as the number of patients reporting an elevation of ALT or AST plasma levels), documented cases of liver failure, causes for tolcapone discontinuation, other AEs, changes of the daily Off-time, changes of the levodopa daily dose, changes of UPDRS part-III scores, score changes of validated scales for evaluating non-motor PD symptoms, score changes of validated scales for evaluating QoL in PD.

If two or more studies reported data from the same population, we included the most recent publication with the longest follow-up. Data were summarized using median and 
range, or percentage as appropriate. Two investigators (C.A.A., L.S.) independently performed the quality appraisal of qualifying studies. Given the heterogeneity of study designs, the risk of bias of each study was evaluated using the National Heart, Lung, and Blood Institute Quality Appraisal Tools as per the Cochrane handbook recommendations [8]. Only data from patients receiving 100 or $200 \mathrm{mg}$ t.i.d. of tolcapone, the two approved dosages, were extracted and presented. When studies reported efficacy data for both dosages, only results from the most effective dosage were presented. Regarding safety data, we reported all relevant information independently from the considered dosage (100 or $200 \mathrm{mg}$ t.i.d.).

\section{Data analysis}

Results were summarized as follows: prevalence of liver enzyme elevation, number of documented cases of liver failure, prevalence of other AEs, and causes of therapy discontinuation for the safety evaluation; changes of the daily number of hours spent in Off, levodopa daily dose, UPDRS-III, QoL, and non-motor symptoms for the clinical efficacy evaluation. In studies where we found only information on the percentage reduction of hours spent in Off, we estimated the change in hours presuming $14 \mathrm{~h}$ of waking day.

\section{Results}

Of 258 eligible studies, 32 met full criteria ( 15 RCTs, 3 crossover trials, 1 non-randomized control trial, 1 RCT post hoc analysis, 1 open-label study on a group of patients enrolled from RCT, 1 controlled before and after study, 4 before and after studies, 3 prospective cohort studies, 1 retrospective cohort study, 1 case-control study, and 1 case report) [9-40] and underwent data extraction and quality assessment (Fig. 3).

Included studies provided data from a total of 4780 patients treated with tolcapone, 4575 when considering only the dose of 100 or $200 \mathrm{mg}$ t.i.d. Thirteen studies (40\%) reported data on control groups treated with placebo, and six studies (18\%) reported data on active control groups, treated with entacapone ( $n=4$ studies), pergolide $(n=1)$, or bromocriptine $(n=1)$.

\section{Safety}

\section{Liver enzyme elevation}

A systematic evaluation of liver enzymes in patients exposed to tolcapone was reported in 21 studies ( 10 RCTs, 1 crossover trial, 1 controlled before and after study, 5 before and after studies, 2 prospective cohort studies, 1 retrospective cohort study, 1 case-control study), including a total of 4181 patients treated with tolcapone, evaluated for a median follow-up of 2.3 months (range 0.5-24) (Table 1).

Eighty-one percent of studies $(n=17 / 21)$ searched for liver enzyme elevation during treatment with tolcapone, with percentage of patients presenting liver enzyme elevation ranging from 0 to $27.5 \%$. In the vast majority of cases, the enzyme elevation was reported as mild and "aspecific," while $0.9 \%$ of patients $(n=36)$ showed an elevation of liver enzymes $>2$ upper limit normal. A total of $0.6 \%$ of patients $(n=23)$ receiving tolcapone withdrew from studies because of liver enzyme elevation.

Thirteen studies reported data on liver enzyme also in control groups of PD patients not treated with tolcapone. Twentythree percent of these studies $(n=3 / 13)$ reported cases of liver enzyme elevation. All three studies had an active control group treated with entacapone $(n=2)$ or pergolide $(n=1)$. The percentage of controls reporting a liver enzyme elevation ranged from 0 to $20.2 \%$.

\section{Liver failure}

No cases of liver failure related to tolcapone administration were reported in RCTs, nor in other observational studies on tolcapone yielded by our systematic review. We found four cases reported in 1998 on liver failure in PD patients treated with tolcapone, with no antecedents of liver dysfunction, which led to the marketing suspension of tolcapone [41]. Only one of these cases was retrieved by our PubMed research as a case report [40], while the others were indirectly reported in a manuscript published by the Tasmar Advisory Panel [41]. A case of fulminant hepatitis has been described in a 74-yearold woman and a disease duration of 20 years, with tolcapone $100 \mathrm{mg} /$ day bid. Concomitant antiparkinsonian treatment was levodopa/benserazide $100 \mathrm{mg} / 25 \mathrm{mg}$ t.i.d. She developed a severe liver failure in 9 weeks. Despite discontinuation of tolcapone, she rapidly deteriorated and she died in hepatic coma 14 days after admission, about 1 month after symptom onset. The second case of liver failure occurred in a 73-yearold woman, taking tolcapone $200 \mathrm{mg}$ t.i.d. and levodopa/ carbidopa (dose not available). She had several comorbidities including aortic regurgitation, septicaemia due to a staphylococcus infection of the back, weight loss, and depression. She developed liver failure 12 weeks after starting tolcapone, but tolcapone was not discontinued and she died 2 weeks later. Similarly, another 74-year-old woman, taking levodopa/ carbidopa 100/25 mg, 8 times/day, developed a liver failure 11 weeks after starting tolcapone $100 \mathrm{mg}$ t.i.d. Tolcapone was halted after 1 week since the onset of symptoms, but few days later she had an episode of coffee-ground emesis in the context of a cirrhosis. She developed an acute distress respiratory syndrome treated with fresh frozen plasma, but she deceased in few days. Finally, a fourth case of liver dysfunction has been reported in a 66-year-old woman, under tolcapone $200 \mathrm{mg}$ 


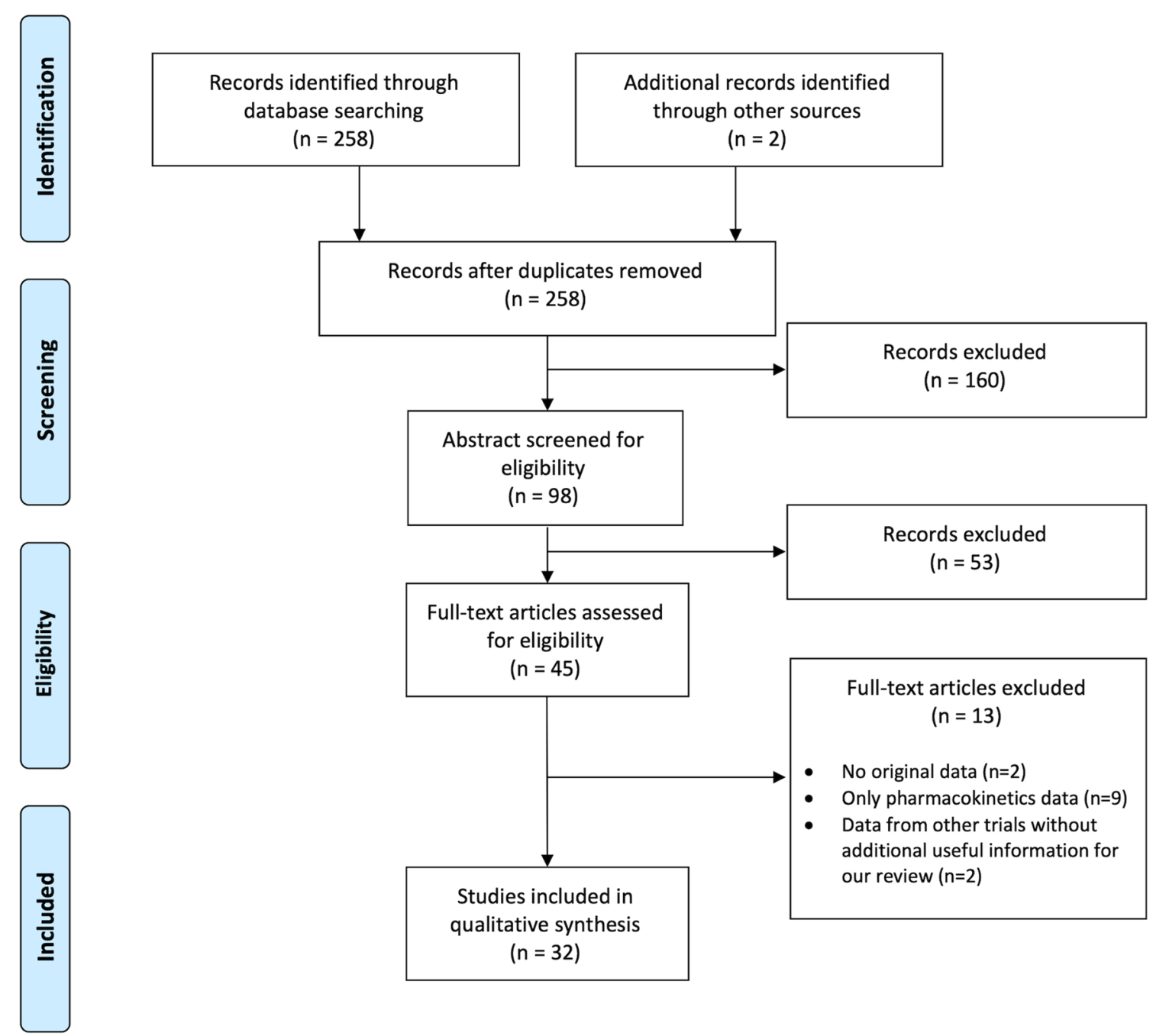

Fig. 3 Flowchart of the systematic review

t.i.d. for about 3 months. She was hospitalized 2 weeks after symptom onset, tolcapone was halted and liver enzymes significantly decreased in 3 days. The liver biopsy did not find evidence of cirrhosis. She was treated with vitamin K, fresh frozen plasma, and prednisone, recovering in a week.

Beyond the abovementioned four clinical cases described in 1998, our systematic review could not find other cases of hepatic fatality. However, other three cases of severe liver injury possibly related to tolcapone were summarized in a safety review of tolcapone in 2007 [42].

The interrogation of the FAERS and EudraVigilance databases for suspected serious AEs during the treatment with tolcapone yielded 61 reports (14 from EudraVigilance and 47 from FAERS) of hepatitis, liver failure, liver toxicity, or jaundice from 1997 to May 15, 2020. Among these, 19 reports described the co-occurrence of major disease or syndromes, such as neuroleptic malignant syndrome, multiple organ failure, neoplasm, shock, sepsis, complicated mononucleosis, and in one case congenital absence of bile ducts. Seven of these reports resulted in death, 10 recovered or had minor sequelae, and 2 cases had unknown outcome. The remaining 42 suspected AEs reports ( 8 from EudraVigilance and 34 from FAERS) showed fatality in 9 cases, unknown outcome in 3 cases, while 30 cases resolved or remained stable; no further detail about sequalae was available. Half of reported cases occurred early in 1998 (Table 2).

\section{Causes of tolcapone discontinuation and other adverse events}

Twenty-nine studies reported data on AEs (all but 1 retrospective cohort study, 1 RCT post hoc analysis, 1 open-label study, on a group of patients enrolled from RCT), for a total of 2748 patients treated with tolcapone and evaluated for a median follow-up of 2.5 months (range $0.5-15$ ) (Table 1). The most common AEs reported were liver enzyme elevation (ranging from 0 to $27 \%$ of patients), diarrhea (from 0 to $29 \%$ ), urine discoloration (from 0 to $23 \%$ ), and dopaminergic symptoms, such as dyskinesia (from 1 to $95 \%$ ), hallucinations (from 0 to $24 \%$ ), nausea (from 0 to $68 \%$ ), and dizziness (from 0 to $16 \%$ ). 


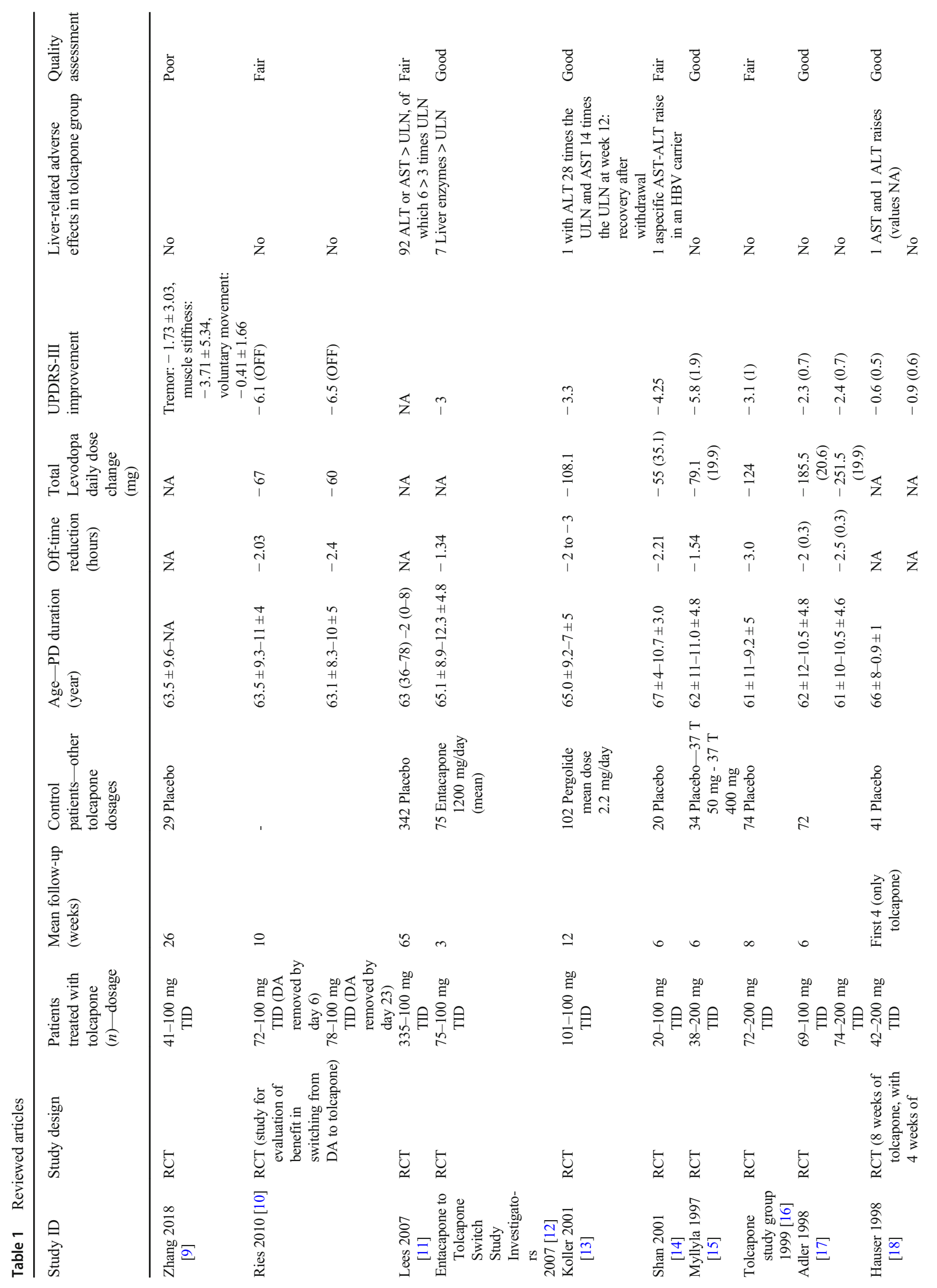




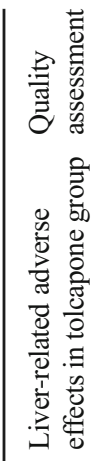

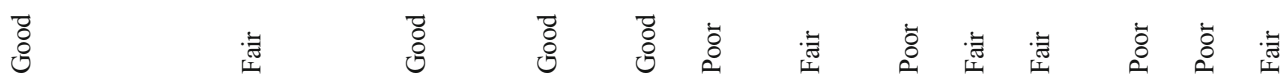

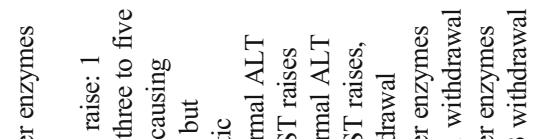

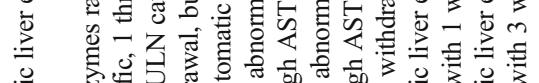

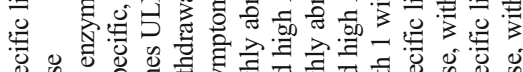

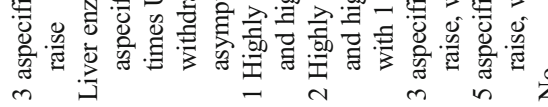

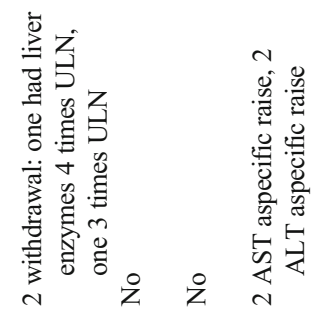

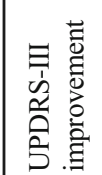

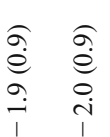

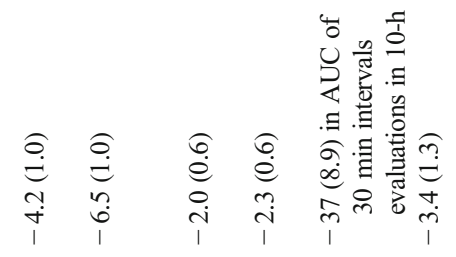

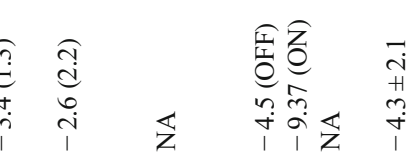

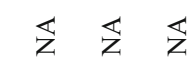

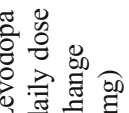

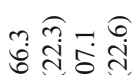

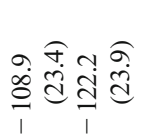

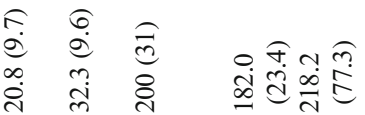

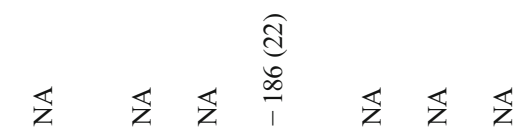
壱总产
$\stackrel{m}{i} \stackrel{i}{1}$

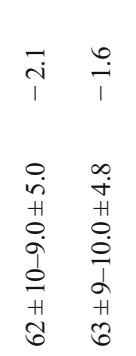

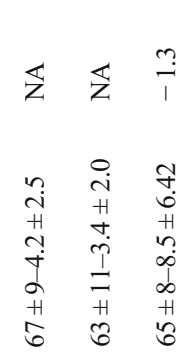

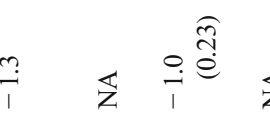
$\overleftrightarrow{z} \mathbb{z} \overleftrightarrow{z}$

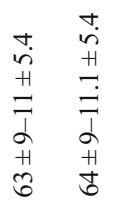

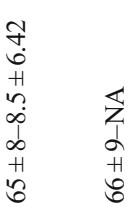

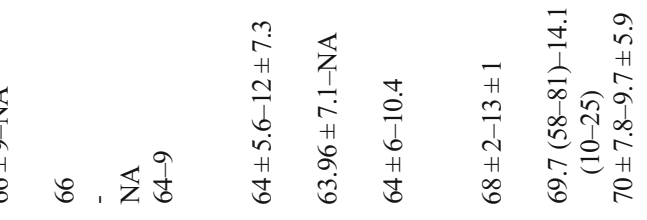

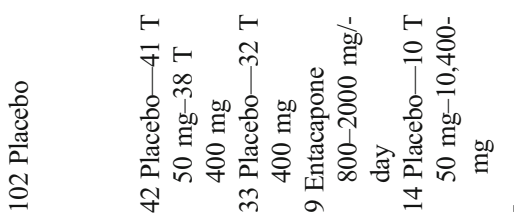
$\frac{8}{\frac{0}{0}}$

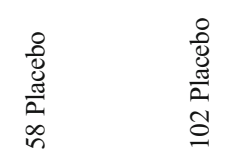
$\underset{\approx}{~}$

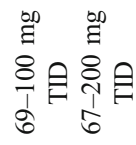

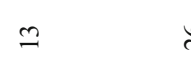
닌

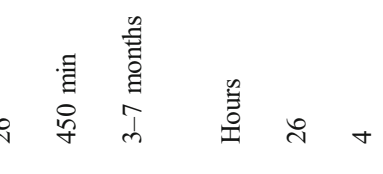

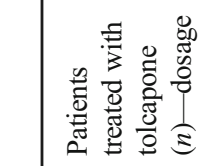

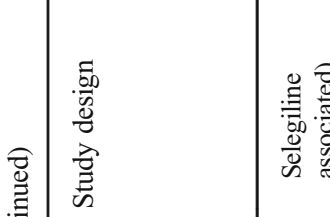
高

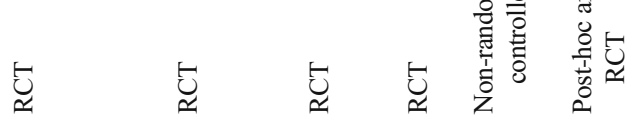

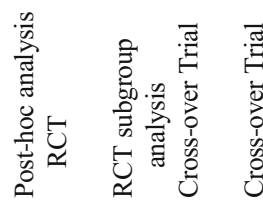

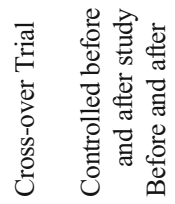

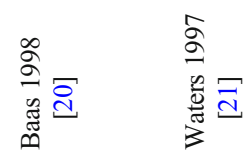

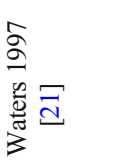

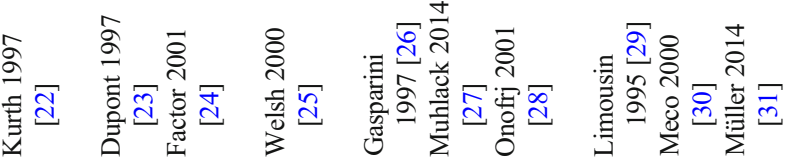

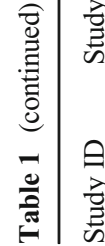




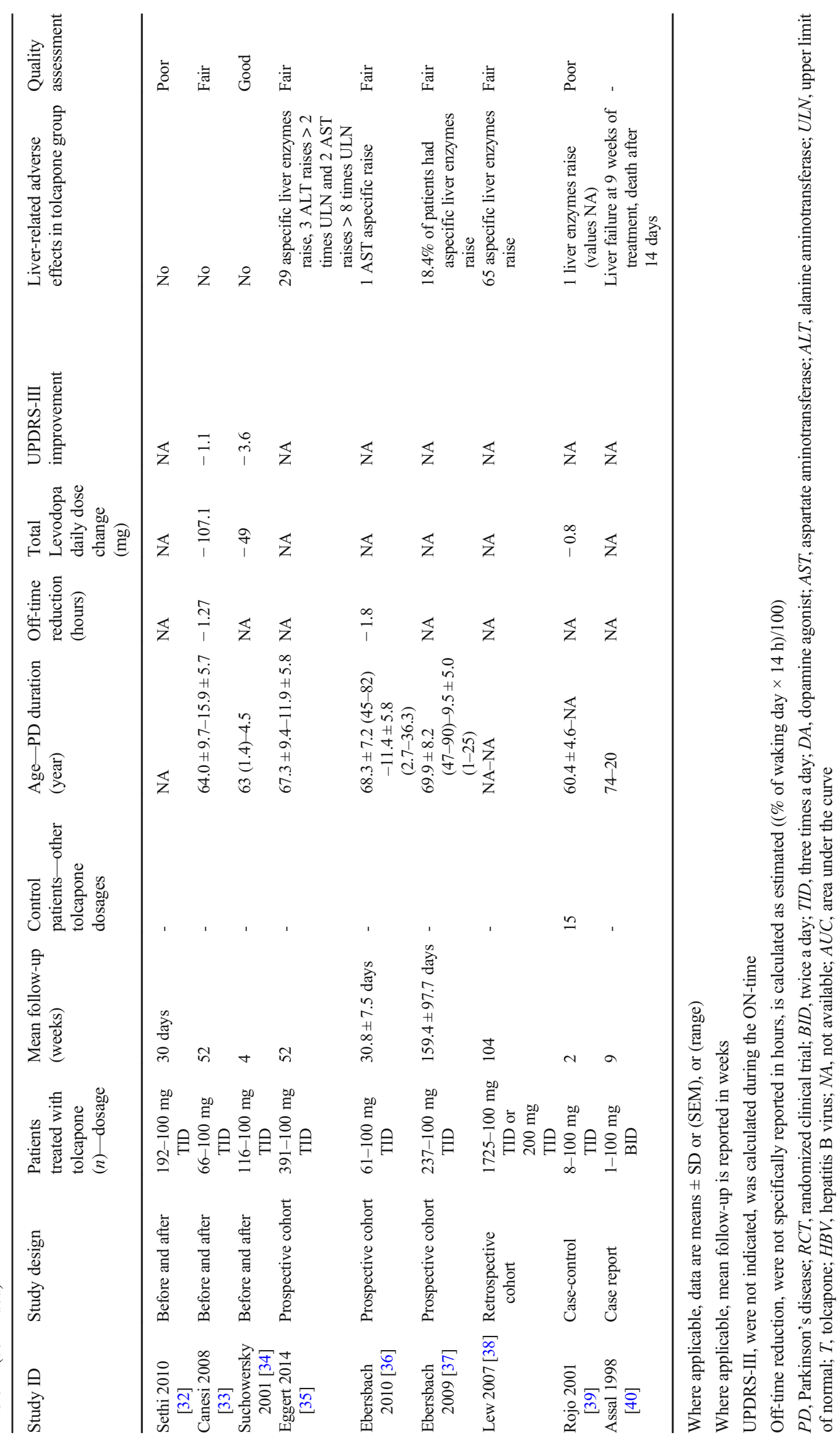


Analyzing AEs in studies comparing the effect of tolcapone with an active control group, there was no significant difference in occurrence and types of AEs between tolcapone and entacapone groups ( $n=2$ studies); there was a higher proportion of AEs related drops-out in the pergolide group; and there was a higher incidence of nausea, orthostatic complaints, hallucinations, and peripheral edema in the bromocriptine group vs. tolcapone, but lower incidence of muscle cramps, dystonia, and xerostomia.

Excluding case reports, 21 studies reported data on patients withdrawing tolcapone with related causes. From studies reporting data on drop-out, a total of $10.3 \%$ of patients $(n=$ 270/2631) withdrew tolcapone due to AEs. The most common causes for tolcapone discontinuation were: diarrhea, liver enzyme elevation, nausea, and dopaminergic symptoms. No cases of liver failure were found, with the exception of one patient with liver metastasis from breast cancer.

Diarrhea was reported in 12 studies as an AE occurring during tolcapone treatment. From these studies, $6.8 \%$ of patients ( $n=94 / 1384$ ) withdrew tolcapone because of diarrhea. Seven out of 12 studies reported AE data from a control group, showing $0.9 \%(n=6 / 666)$ of control drop-out due to diarrhea.

\section{Efficacy}

\section{Reduction of daily time spent in Off}

Twelve studies reported data on daily hours spent in Off (9 RCTs, 1 cross-over trial, 1 before and after study, 1 prospective cohort study), for a total of 967 patients treated with tolcapone evaluated for a median follow-up of 1.7 months (range 0.7-7) (Table 1). The median reduction of hours/day spent in Off was 2.1, ranging from 1 to 3.2. Whenever applicable, $100 \%$ of studies reported a significant reduction of the Off hours after administration of tolcapone (within group difference). Twelve studies reported data on daily Off change comparable with a group of patients in levodopa plus placebo $(n=7)$ or levodopa plus bromocriptine $(n=1)$, pergolide $(n=$ $1)$, or entacapone $(n=3)$ (between groups difference). All but one studies vs. placebo found a significant difference between patients treated with tolcapone and the control group. Two out of three studies vs. entacapone reported a significant higher reduction of Off hours in the tolcapone group, while the 2 studies comparing tolcapone with dopamine-agonists pergolide and bromocriptine found a similar extent of improvement.

\section{Reduction of levodopa daily dose}

Sixteen studies reported data on levodopa daily dose (11 RCTs, 1 cross-over trials, 1 non-randomized control trial, 2 before and after studies, 1 case-control study), for a total of 995 patients treated with tolcapone evaluated for a median follow-up of 2.5 months (range $0.5-12$ ) (Table 1). The median reduction of levodopa was $108.9 \mathrm{mg}$, ranging from 1 to $251.5 \mathrm{mg}$. Six studies reported a significant reduction of levodopa dose after tolcapone starting. Twelve studies reported data on levodopa daily dose comparable with a group of patients in levodopa plus placebo $(n=8)$ or levodopa plus bromocriptine $(n=1)$, pergolide $(n=1)$, or entacapone $(n=2)$. Seventy-five percent of studies vs. placebo $(n=6 / 8)$ found a significant lower levodopa daily dose between patients treated with tolcapone and the control group. The two studies vs. entacapone and the study vs. bromocriptine reported a significant higher reduction of levodopa in the tolcapone group, while the study comparing tolcapone with pergolide found a similar extent of levodopa dose reduction.

\section{Improvement of UPDRS motor score}

Seventeen studies reported data on UPDRS-III changes over time (12 RCTs, 1 cross-over trials, 1 non-randomized control trial, 1 open-label study on a group of patients enrolled from RCT, 2 before and after studies), for a total of 1113 patients treated with tolcapone evaluated for a median follow-up of 2.2 months (range 0.7-12) (Table 1). A percentage of 64.7 of studies $(n=11 / 17)$ reported the UPDRS-III score in the On condition, $11.8 \%(n=2 / 17)$ in both the Off and On conditions, and $5.9 \%(n=1 / 17)$ in the Off condition; $17.6 \%$ of studies $(n=3 / 17)$ did not specify whether UPDRS-III scores were in the Off or On condition. The median reduction of UPDRS-III in On was -3.6 points, ranging from -1.1 to 6.5. Five studies evaluated whether the UPDRS-III change between pre and post tolcapone administration was significant, and all but one of these studies found a significant improvement after tolcapone administration, after a median follow-up of 5 months (range 1-12). One additional study evaluating "acute" UPDRS-III score changes till $420 \mathrm{~min}$ after the administration of tolcapone found a significant UPDRS-III improvement [27].

Fourteen studies reported data on UPDRS-III score changes comparable with a group of patients in levodopa plus placebo $(n=8)$ or levodopa plus bromocriptine $(n=1)$, pergolide $(n=1)$, or entacapone $(n=4)$. Thirty-seven percent of studies vs. placebo $(n=3 / 8)$ found a significant difference between patients treated with tolcapone and the control group in favor of tolcapone patients. The studies analyzing the tolcapone group vs. an active control group did not find significant difference in the UPDRS-III score changes.

\section{Improvement of QoL}

Nine studies reported data on QoL (5 RCTs, 1 RCT post hoc analysis, 2 before and after studies, 1 prospective cohort study), for a total of 801 patients treated with tolcapone evaluated for a median follow-up of 2.5 months (range 1-6). There 
Table 2 Adverse events during tolcapone available on FDA and EUDRA reporting system

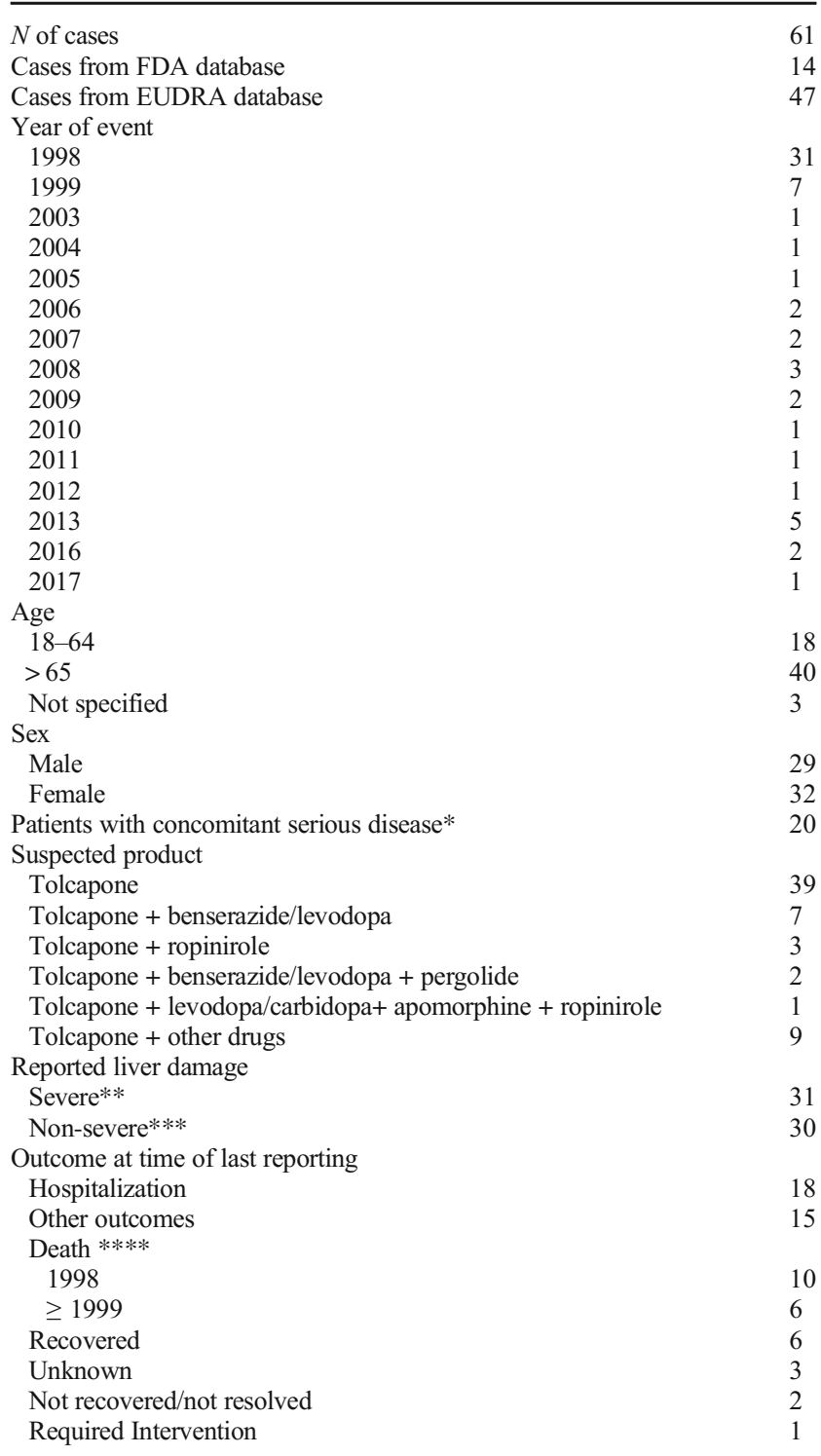

*Concomitant serious disease: neuroleptic malignant syndrome; congenital absence of bile ducts; intestinal infarction; rhabdomyolysis; shock; cardiac failure; cancer; cirrhosis; renal failure; mononucleosis; nonHodgkin's lymphoma; sepsis; infection; medication error; pancreatitis; hepatorenal failure; pleural fibrosis; stroke; atelectasia; pneumonia

**Severe liver damage reported: hepatitis fulminant; hepatitis; acute hepatic failure; hepatic failure; hepatic necrosis; hepatic encephalopathy; hepatic cirrhosis; portal hypertension; hepatorenal failure; biliary cirrhosis

***Non-severe liver damage reported: jaundice; cholestatic liver injury; liver function test abnormal; hepatotoxicity; alanine aminotransferase increased; aspartate aminotransferase increased; blood bilirubin increased; blood alkaline phosphatase increased; gamma-glutamyltransferase increased; hepatic enzyme increased; drug-induced liver injury; hepatomegaly; cholelithiasis; liver disorder; hepatic steatosis; cholecystitis; hyperammonaemia

***** Of the 16 death patients, 10 had concomitant serious disease, and 1 was positive for antimitochondrial antibodies was heterogeneity on the assessment of QoL: 5 studies evaluated QoL changes by the Sickness Impact Profile (SIP), 2 studies by the EuroQol-5D, 1 study by the Parkinson's disease questionnaire 8 (PDQ-8), and 1 study by both the SIP and the PDQ-39. Independently on the type of assessment, $80 \%$ of studies reporting the information $(n=4 / 5)$ found a significant improvement of QoL after administration of tolcapone. Five studies reported data on QoL changes comparable with a group of patients in levodopa plus placebo $(n=4)$ or levodopa plus pergolide $(n=1)$. Fifty percent of studies vs. placebo $(n=$ 2/4) found a significant difference between patients treated with tolcapone and the control group in favor of tolcapone patients, and also the study comparing tolcapone vs. pergolide found a significantly higher improvement of QoL in patients treated with tolcapone.

\section{Improvement of non-motor symptoms}

Ten studies reported data on non-motor symptoms (6 RCTs, 1 cross-over trials, 1 open-label study on a group of patients enrolled from RCT, 1 before and after study, 1 prospective cohort study), for a total of 554 patients evaluated for a median follow-up of 3 months (range 1-7). There was heterogeneity on the assessment of non-motor symptoms: only 1 study employed a specific scale validated for the assessment of non-motor symptoms, the "Non-motor Symptoms Questionnaire" (NMSQ) [31]. Eight studies reported nonmotor data by UPDRS-I score, 1 study employed specific scale to assess the sleep quality (Parkinson's disease sleep scale (PDSS), and Epworth sleepiness scale (ESS)) [36], and 1 study analyzed differences in cognitive functions by means of a comprehensive battery of neuropsychological tests [26].

The study analyzing non-motor symptoms by NMSQ and UPDRS-I found a significant improvement of patients 1 month after starting tolcapone in both scales, with a mean reduction of 2.5 points for the NMSS and 1 point for the UPDRS-I. The 2 other studies, using UPDRS-I and reporting information on significant difference before and after tolcapone, did not report a significant improvement. The study assessing the sleep reported a significant improvement of both PDSS and ESS, with a mean score reduction of -15.3 and -1.3 , respectively. The study assessing cognitive functions of 8 PD patients at baseline and after 6 months of treatment with tolcapone found improvement in attentional task, auditory verbal short-term memory, visuo-spatial recall, and constructional praxia.

Five studies reported data on non-motor symptom changes comparable with a group of patients in levodopa only and no studies compared this outcome with active control groups. Twenty percent of studies $(n=1 / 5)$ found a significant higher improvement of symptoms (as per UPDRS-I score) than placebo group. 


\section{Discussion}

We performed a systematic review of studies reporting clinical data on the safety and efficacy of tolcapone as an adjunct therapy to levodopa at the dosage of 100 or $200 \mathrm{mg}$ t.i.d. We found that from 21 studies, of which 10 RCTs, reporting data of 4181 tolcapone treated patients, an elevation of mild liver enzymes was frequent (ranging from 0 to $27 \%$ of patients), but elevation $>2$ upper limit normal was reported in $<1 \%$ of patients. Three RCTs comparing efficacy and safety of tolcapone with other add-on therapies (entacapone in 2 studies and pergolide in 1 study) reported elevation of liver enzymes also in the control group. Three cases of fatal liver failure and one case of severe reversible hepatotoxicity were reported in 1998 [40, 41]. Noteworthy, none of these patients had followed monitoring guidelines, and in one case tolcapone was not withdrawn even after the development of clinical evidence of hepatic failure [41]. After these cases, in the last 20 years we could find only three, not fatal cases of severe liver injury possibly related to tolcapone [42] and no other studies on PubMed reporting relevant safety issues with tolcapone. However, we retrieved 61 further reports of severe AEs involving the liver registered in the EMA and FDA databases for post-authorization drug surveillance. The interpretation of data extracted from these databases requests important caveats. First, the causality link between the drug and the reaction cannot be deduced from data since the report reflects only a subjective observation by the reporter. Furthermore, the submission of a report does not undergo to formal revision or medical check, the reporter could be a non-healthcare professional, data could be incomplete, and information could be duplicated if more than one reporter independently submit the same case. Nevertheless, these data disclose precious information concerning possible adverse reactions that otherwise would be lost.

Excluding the hepatic concern, the safety profile of tolcapone can be considered comparable to other COMT inhibitors, including a low drop-out rate for dyskinesia, being the most frequent cause of treatment discontinuation in patients under opicapone $50 \mathrm{mg} /$ day [43].

Concerning the efficacy, the median reduction of hours spent in Off was 2.1, which is significant in the vast majority of studies also compared to placebo or entacapone. Such a data is consistent with the Cochrane meta-analysis on add-on levodopa treatment effect, which reports on an Off-time reduction of $-1.6 \mathrm{~h} /$ day (CI 95\% -2.0 to -1.2 ) for tolcapone [3]. These values place tolcapone as the most effective COMT inhibitor in terms of motor fluctuations, if compared to entacapone and the recently marketed opicapone, providing an Off-time reduction of about -0.61 and $-1 \mathrm{~h} /$ day, respectively [44]. While direct comparisons between tolcapone and entacapone showed the higher efficacy of the former, the superiority of tolcapone on opicapone should be better supported by a head-to-head trial comparison.

Data on motor fluctuations and dyskinesia provided by UPDRS-IV was fully available only in 2 out of 32 studies and thus we could not provide a reliable analysis of this outcome. However, the great efficacy of tolcapone is further supported by a median reduction of levodopa of $108.9 \mathrm{mg}$, which was higher than patients treated with entacapone and bromocriptine in three studies, and by a UPDRS-III score in On improved of a median of -2.8 points, which can be considered a clinically meaningful change [45]. Moreover, QoL significantly improved in $50 \%$ of studies comparing tolcapone versus placebo, and in one study comparing tolcapone vs. pergolide. Finally, studies investigating non-motor symptoms found efficacy of tolcapone on total NMSQ and UPDRS-I scores, although drawing conclusions on the effect of tolcapone on single non-motor symptoms is not possible. Results from one study suggested a sleep improvement as per the significant improvement of both PDSS and ESS scale scores, and another study found a global cognitive improvement of patients treated with tolcapone $[26,36]$. The improvement of these specific non-motor symptoms might be related to the concomitant reduction of motor fluctuations and the improvement of parkinsonian symptoms.

After more than 20 years from its first approval and about 14 years after its reintroduction into the market, we have a deeper knowledge of the tolcapone safety profile, which allows clinicians to safely manage and properly monitor possible liver AEs. Even if tolcapone is still considered a secondline levodopa add-on treatment [6], mainly due to past safety concerns, we have observed that liver enzyme elevation, which can be frequent, is considered mild or aspecific in about $99 \%$ of cases. Indeed, a very low number of patients developed liver injuries after tolcapone remarketing with the new guidelines for liver function monitoring (Fig. 2) (https://www. ema.europa.eu/en/documents/product-information/tasmarepar-product-information_en.pdf). A multi-center, observational study on 391 patients treated with tolcapone under routine practice conditions, showed that tolcapone is safe in PD patients following the guidelines for monitoring liver enzymes, proving that significant liver transaminase elevations were rare and generally returned to normal without intervention in most patients [35]. Moreover, Lees and coll. [11] analyzed the safety and tolerability profile of tolcapone enrolling 667 levodopa-naive patients with earlystage PD and randomized to receive placebo or tolcapone $100 \mathrm{mg}$ t.i.d, added to standard doses of levodopa; they found liver values above the upper limit normal in $20.2 \%$ of patients receiving levodopa plus placebo and $27.5 \%$ in the tolcapone group, including those with increased values at screening; increases 3 times the upper limit normal occurred in $1.8 \%$ of tolcapone treated patients and $1.2 \%$ of placebo treated patients (the difference was not statistically significant). 
This systematic review has two main shortcomings that should be taken into account when interpreting the results. First, we limited our search to the PubMed database, and some pertinent studies, including gray literature, could have been missed. Second, we did not apply a meta-analytic data analysis. This aspect should be especially considered when interpreting comparisons of data between tolcapone and other COMT inhibitors.

Limitations notwithstanding, available evidence indicates that tolcapone is a highly effective add-on therapy for PD, without relevant safety concerns when adherence to the FDA and EMA prescription guidelines is respected.

Supplementary Information The online version contains supplementary material available at https://doi.org/10.1007/s00228-020-03081-x.

Authors' contributions Carlo Alberto Artusi: design and conceptualized study; analyzed and interpreted the data; drafted the manuscript for intellectual content. Lidia Sarro: analyzed and interpreted the data; revised the manuscript for intellectual content. Gabriele Imbalzano: analyzed and interpreted the data; revised the manuscript for intellectual content. Margherita Fabbri: analyzed and interpreted the data; drafted the manuscript for intellectual content. Leonardo Lopiano: design and conceptualized study; revised the manuscript for intellectual content.

Funding Open Access funding provided by Università degli Studi di Torino.

Data availability All data used for this review are provided in the main text and tables. Sources of data are referenced in the appropriate section.

\section{Compliance with ethical standards}

Conflict of interest Dr. Artusi received travel grants from Zambon and Abbvie, and educational grants from Ralpharma and Neuraxpharm.

Dr. Sarro reports no financial disclosures.

Dr. Imbalzano reports no financial disclosures.

Dr. Fabbri received speaker honoraria from Abbvie.

Prof. Lopiano received honoraria for lecturing and travel grants from, UCB Pharma, AbbVie, DOC, Zambon and Bial.

Open Access This article is licensed under a Creative Commons Attribution 4.0 International License, which permits use, sharing, adaptation, distribution and reproduction in any medium or format, as long as you give appropriate credit to the original author(s) and the source, provide a link to the Creative Commons licence, and indicate if changes were made. The images or other third party material in this article are included in the article's Creative Commons licence, unless indicated otherwise in a credit line to the material. If material is not included in the article's Creative Commons licence and your intended use is not permitted by statutory regulation or exceeds the permitted use, you will need to obtain permission directly from the copyright holder. To view a copy of this licence, visit http://creativecommons.org/licenses/by/4.0/.

\section{References}

1. Kurth MC, Adler CH (1998) COMT inhibition: a new treatment strategy for Parkinson's disease. Neurology 50:S3-S14
2. Dingemanse J, Jorga K, Zurcher G et al (1995) Pharmacokineticpharmacodynamic interaction between the COMT inhibitor tolcapone and single-dose levodopa. Br J Clin Pharmacol 40:253262

3. Stowe R, Ives N, Clarke CE et al (2010) Evaluation of the efficacy and safety of adjuvant treatment to levodopa therapy in Parkinson s disease patients with motor complications. Cochrane Database Syst Rev 7:CD007166

4. Fabbri M, Ferreira JJ, Lees A, Stocchi F, Poewe W, Tolosa E, Rascol O (2018) Opicapone for the treatment of Parkinson's disease: a review of a new licensed medicine. Mov Disord 33:15281539

5. Ceravolo R, Piccini P, Bailey DL, Jorga KM, Bryson H, Brooks DJ (2002) 18F-dopa PET evidence that tolcapone acts as a central COMT inhibitor in Parkinson's disease. Synapse 43:201-207

6. Fox SH, Katzenschlager R, Lim SY et al (2018) International Parkinson and movement disorder society evidence-based medicine review: update on treatments for the motor symptoms of Parkinson's disease. Mov Disord 33:1248-1266

7. Moher D, Liberati A, Tetzlaff J, Altman DG, PRISMA Group (2009) Preferred reporting items for systematic reviews and metaanalyses: the PRISMA statement. PLoS Med 6:e1000097

8. Higgins JP, Altman DG, Gøtzsche PC et al (2011) The Cochrane Collaboration's tool for assessing risk of bias in randomised trials. BMJ 343:d5928

9. Zhang PL, Wang YX, Chen Y, Zhang CH, Li CH (2018) The efficacy of homemade tolcapone in the treatment of patients with Parkinsons disease. Exp Ther Med 15:127-130

10. Ries V, Selzer R, Eichhorn T, Oertel WH, Eggert K, German Tolcapone Study Group (2010) Replacing a dopamine agonist by the COMT-inhibitor tolcapone as an adjunct to L-dopa in the treatment of Parkinson's disease: a randomized, multicenter, open-label, parallel-group study. Clin Neuropharmacol 33:142-150

11. Lees AJ, Ratziu V, Tolosa E, Oertel WH (2007) Safety and tolerability of adjunctive tolcapone treatment in patients with early Parkinson's disease. J Neurol Neurosurg Psychiatry 78:944-948

12. Entacapone to Tolcapone Switch Study Investigators (2007) Entacapone to tolcapone switch: multicenter double-blind, randomized, active-controlled trial in advanced Parkinson's disease. Mov Disord 22:14-19

13. Koller W, Lees A, Doder M, Hely M, Tolcapone/Pergolide Study Group (2001) Randomized trial of tolcapone versus pergolide as add-on to levodopa therapy in Parkinson's disease patients with motor fluctuations. Mov Disord 16:858-866

14. Shan DE, Lee SJ, Chao LY, Yeh SI (2001) Gait analysis in advanced Parkinson's disease-effect of levodopa and tolcapone. Can J Neurol Sci 28:70-75

15. Myllylä VV, Jackson M, Larsen JP, Baas H, Tolcapone International Parkinson's Disease Study (TIPS) Group I (2011) Efficacy and safety of tolcapone in levodopa-treated Parkinson's disease patients with "wearing-off" phenomenon: a multicentre, double-blind, randomized, placebo-controlled trial. Eur J Neurol 4:333-341

16. Tolcapone Study Group (1999) Efficacy and tolerability of tolcapone compared with bromocriptine in levodopa-treated parkinsonian patients. Mov Disord 14:38-44

17. Adler CH, Singer C, O'Brien C et al (1998) Randomized, placebocontrolled study of tolcapone in patients with fluctuating Parkinson disease treated with levodopa-carbidopa. Tolcapone Fluctuator Study Group III. Arch Neurol 55:1089-1095

18. Hauser RA, Molho E, Shale H, Pedder S, Dorflinger EE (1998) A pilot evaluation of the tolerability, safety, and efficacy of tolcapone alone and in combination with oral selegiline in untreated Parkinson's disease patients. Tolcapone De Novo Study Group Mov Disord 13:643-647 
19. Rajput AH, Martin W, Saint-Hilaire MH, Dorflinger E, Pedder S (1998) Tolcapone improves motor function in parkinsonian patients with the "wearing-off" phenomenon: a double-blind, placebo-controlled, multicenter trial. Neurology 50:S54-59

20. Baas H, Beiske AG, Ghika J et al (1998) Catechol-Omethyltransferase inhibition with tolcapone reduces the "wearing off" phenomenon and levodopa requirements in fluctuating parkinsonian patients. Neurology 50:S46-S53

21. Waters CH, Kurth M, Bailey P et al (1997) Tolcapone in stable Parkinson's disease: efficacy and safety of long-term treatment. The Tolcapone Stable Study Group. Neurology 49:665-671

22. Kurth MC, Adler CH, Hilaire MS et al (1997) Tolcapone improves motor function and reduces levodopa requirement in patients with Parkinson's disease experiencing motor fluctuations: a multicenter, double-blind, randomized, placebo-controlled trial. Tolcapone Fluctuator Study Group I. Neurology 48:81-87

23. Dupont E, Burgunder JM, Findley LJ, Olsson JE, Dorflinger E (1997) Tolcapone added to levodopa in stable parkinsonian patients: a double-blind placebo-controlled study. Tolcapone in Parkinson's Disease Study Group II (TIPS II). Mov Disord 12: 928-934

24. Factor SA, Molho ES, Feustel PJ, Brown DL, Evans SM (2001) Long-term comparative experience with tolcapone and entacapone in advanced Parkinson's disease. Clin Neuropharmacol 24:295299

25. Welsh MD, Dorflinger E, Chernik D, Waters C (2000) Illness impact and adjustment to Parkinson's disease: before and after treatment with tolcapone. Mov Disord 15:497-502

26. Gasparini M, Fabrizio E, Bonifati V, Meco G (1997) Cognitive improvement during tolcapone treatment in Parkinson's disease. J Neural Transm (Vienna) 104:887-894

27. Muhlack S, Herrmann L, Salmen S, Müller T (2014) Fewer fluctuations, higher maximum concentration and better motor response of levodopa with catechol-O-methyltransferase inhibition. J Neural Transm (Vienna) 121:1357-1366

28. Onofrj M, Thomas A, Iacono D, Di Iorio A, Bonanni L (2001) Switch-over from tolcapone to entacapone in severe Parkinson's disease patients. Eur Neurol 46:11-16

29. Limousin P, Pollak P, Pfefen JP, Tournier-Gervason CL, Dubuis R, Perret JE (1995) Acute administration of levodopa-benserazide and tolcapone, a COMT inhibitor, Parkinson's disease. Clin Neuropharmacol 18:258-265

30. Meco G, Vanacore N, Locuratolo N et al (2000) Heart rate variability in Parkinson's disease patients treated with tolcapone. Parkinsonism Relat Disord 6:223-227

31. Müller T, TANIMOS Study Investigators (2014) Tolcapone addition improves Parkinson's disease associated nonmotor symptoms. Ther Adv Neurol Disord 7:77-82
32. Sethi K, Factor S, Watts R (2010) Quality of life in Parkinson's disease patients following adjunctive tolcapone therapy: results of an open-label, multicenter, community-based trial. CNS Spectr 15 : 27-32

33. Canesi M, Zecchinelli AL, Pezzoli G, Antonini A (2008) Clinical experience of tolcapone in advanced Parkinson's disease. Neurol Sci 29:S380-S382

34. Suchowersky O, Bailey P, Pourcher E, Bulger L, Facciponte G (2001) Comparison of two dosages of tolcapone added to levodopa in nonfluctuating patients with PD. Clin Neuropharmacol 24:214 220

35. Eggert K, Oertel WH, Lees AJ, German Competence Network on Parkinson's disease (2014) Safety and efficacy of tolcapone in the long-term use in Parkinson disease: an observational study. Clin Neuropharmacol 37:1-5

36. Ebersbach G, Hahn K, Lorrain M, Storch A (2010) Tolcapone improves sleep in patients with advanced Parkinson's disease (PD). Arch Gerontol Geriatr 51:e125-e128

37. Ebersbach G, Storch A (2009) Tolcapone in elderly patients with Parkinson's disease: a prospective open-label multicenter noninterventional trial. Arch Gerontol Geriatr 49:e40-e44

38. Lew MF, Kricorian G (2007) Results from a 2-year centralized tolcapone liver enzyme monitoring program. Clin Neuropharmacol 30:281-286

39. Rojo A, Fontán A, Mena MA, Herranz A, Casado S, de Yébenes JG (2001) Tolcapone increases plasma catecholamine levels in patients with Parkinson's disease. Parkinsonism Relat Disord 7:93-96

40. Assal F, Spahr L, Hadengue A, Rubbia-Brandt L, Burkhard PR (1998) Tolcapone and fulminant hepatitis. Lancet 352:958

41. Olanow CW (2000) Tolcapone and hepatotoxic effects. Tasmar Advisory Panel. Arch Neurol 57:263-267

42. Olanow CW, Watkins PB (2007) Tolcapone: an efficacy and safety review. Clin Neuropharmacol 30:287-294

43. Castro Caldas A, Teodoro T, Ferreira JJ (2018) The launch of opicapone for Parkinson's disease: negatives versus positives. Expert Opin Drug Saf 17:331-337

44. Fabbri M, Rosa MM, Ferreira JJ (2018) Adjunctive therapies in Parkinson's disease: how to choose the best treatment strategy approach. Drugs Aging 35:1041-1054

45. Hauser RA, Auinger P, Parkinson Study Group (2011) Determination of minimal clinically important change in early and advanced Parkinson's disease. Mov Disord 26:813-818

Publisher's note Springer Nature remains neutral with regard to jurisdictional claims in published maps and institutional affiliations. 